\title{
Risk of Burden on a Carer of a Patient With Alzheimer's Type Dementia in the Family
}

I. Ondriova (Iveta Ondriova), T. Fertalova (Terezia Fertalova)

University of Presov in Presov, Faculty of Health Care Presov, Department of

Original Article Nursing, Presov, Slovakia.

\section{E-mail address:}

iondriova@centrum.sk

\section{Reprint address:}

Iveta Ondriova

University of Presov in Presov

Faculty of Health Care Presov

Department of Nursing

Partizanska 1

08001 Presov

Slovakia

Source: Clinical Social Work and Health Intervention

Volume: 11

Issue: 3

Pages: 45 - 50

Cited references: 14

\section{Reviewers:}

Andrea Shahum

University of North Carolina at Chapel Hill School of Medicine, USA

Pawel S. Czarnecki

Rector of the Warsaw Management University, Poland

\section{Keywords:}

Alzheimer's Disease. Dementia. Carer. Care. Burden.

\section{Publisher:}

International Society of Applied Preventive Medicine i-gap

CSWHI 2020; 11(3): 45 - 50; DOI: 10.22359/cswhi_11_3_07 (C) Clinical Social Work and Health Intervention

\section{Abstract:}

Alzheimer's disease is a dementia of neurodegenerative origin. Managing care for patients with Alzheimer's dementia is a serious socio economic and social problem. Everyday care for Alzheimer's illness is extremely demanding. Adequate nursing care in home care is difficult as a non-professional suddenly thrust into the role of carer does not have the necessary education or skills to provide it. 


\section{Theoretical basis}

Alzheimer's disease is a serious neurodegenerative brain disorder, leading to the decline of some populations of neurones and consequently to brain atrophy (loss of nerve tissue). This then results in the development of dementia syndrome. This cause of dementia is the most common of all. It accounts for approximately $50 \%$ of all dementias (Klimova 2011).

\section{Clinical Picture of Alzheimer's Disease}

Dementia develops in a non-obvious way, „surreptitiously“. From the beginning, it is usually manifested and diagnosed as a mild disorder of cognitive functions. The first symptoms are memory disturbances, especially of the shortterm memory. Relatively little distortion of orientation in space and time occurs during the course of development of dementia. During the development of Alzheimer's, they begin to forget names, terms and there is a substantial reduction of vocabulary. There is a substantial decline in intellect, thinking slows down. Disorders of the phatic functions (all types of aphasia) may occur (Broadal 2008).

Dementias of the Alzheimer's type can be divided schematically into three levels:

Mild dementia is marked by disorders of memory, which are partly subjective (the patient is aware of a loss of memory), but also objectively measurable using testing methods. Disorders of the declarative memory occur, especially in the short and medium term - failures in remembering new information as well as disruption of daily life activities, especially in the professional sphere and more complex activities. Disorders of orientation may be observed, especially in places which are more remote and less visited by the patient. Mood disorders (mainly depression) are common. Moderate dementia is marked by a major deterioration of memory in all components. Disorientation in time and space is common (Klimova 2011).

Severe dementia is marked by severe impairment to all components of memory. Sufferers are unable to remember new information, are completely disoriented, unable to remember where their bed, their room and the toilet are. They do not recognize people around themselves, often not even their closest relatives Sheardova 2011

\section{Treatment of Alzheimer's Disease}

Procedures for treating Alzheimer's can be divided into 2 categories: biological and non-biological, and in practice it is suitable to combine both methods.

The most common biological treatment approach is pharmacotherapy. Pharmacotherapy for Alzheimer's is cognitive -primarily affecting impairment to the cognitive functions and noncognitive, aimed at influencing the associated disorders of mood and affectation, behaviour, sleep which are often found in patients with Alzheimer's. Klimova 2011 Klimova Magurova 2013

Non- cognitive pharmacotherapy influences behavioural disorders in dementia, changes of mood and affectation, and sleeping disorders. For calming restlessness or even associated delirium, modern substances known as $2^{\text {nd }}$ generation antipsychotics are used, which have a minimum of undesirable side effects. Modern antidepressants (medicines acting against depression) and modern anxiolytics (medicines for anxiety) are also used. Alongside pharmacotherapy, an essential role in the treatment of Alzheimer's is played by the non-pharmacological management of dementia, with a large number of programmes of activities prepared, cognitive training and cognitive therapy and kinesiotherapy. Racs 2009

\section{Psychological and Physical Burden on Carers.}

Long-term care of a non-independent person can be burdensome in many ways. The occurrence of care burden is more frequent in women than in men and this can also be related to the division of „female“ and „male“ activities. While men perform heavier work in the home and provide financial security, women do more domestic work (e.g. shopping, cooking, cleaning, ensuring the entire household runs properly) that is often time consuming. They often get into a situation where they have to look after their children, manage their job and look after their sick, non-independent elderly family members. The changes that the patient and the carer have to undergo after diagnosing Alzheimer's disease are reflected in the need to provide some support in care. The burden on the carer can be divided into an objective and subjective component. The objective factors creating an excessive psychological burden on carers include the length of care, cohabitation in 
a shared household, the degree of dependence of the dependent person, the time required for daily care and the type of disability. The subjective burden on carers depends on their own experience of their role. Reactions to individual stressors are influenced by various psychosocial factors such as family relationships, the social environment and cultural habits. Varsik et al 2011

\section{EMPIRICAL SECTION}

\section{Definition of the research problem and aims.}

The empirical part consists of research in which we mapped the workload of carers in relation to treating a sick relative. We used the Svanborg Nursing Burden Test for mapping the workload of carers in relation to treating a sick relative. The test includes eight activities that the caregiver encounters every day with Alzheimer's disease: mobility, personal hygiene, eating, urinary incontinence, faecal incontinence, use of toilets, pressure sores and cooperation with the patient. The test score determines whether the patient is self-sufficient - 0 points or dependent 38 points. For each activity, respondents could choose from several options. (In the paper we present results for 4 items.)

\section{Aim of the research}

The aim of our research was to map the level of workload in families providing care to relatives suffering from dementia.

Hypothesis. We expect, that carers will have differing levels of work burden from careing for a sick family member with Alzheimer's depending on the stage of the disease. This hypothesis was evaluated using the Svanborg Nursing Burdern Survey on various activities related to the care of a patient with Alzheimer's disease, and we will be interested in whether and how the stage of the disease influences the burden on the carer.

In order to express the correlation between the burden and disease statistics, we use Kendall's rank correlation coefficient $\tau$ (1948) which measures the strength of this correlation. To interpret the coefficient we will use the scale created by Cohen (1988) where correlation below 0.1 is trivial, 0.1-0.3 is small, 0.3-0.5 medium and above 0.5 strong. In addition, we will test the statistical significance of this addiction, i.e. the hypothesis that $\tau=0$. If this hypothesis is not confirmed as the p-value of this test is less than 0.05, we are talking about a statistically significant correlation.

\section{Research methods and methodology}

Description of research sample. The research had 55 participants in different age categories (mean age 49) who were looking after a close relative with Alzheimer's disease.

Organization of the research. The research was performed during the time between October and December 2015. The respondent was a nonprofessional carer for a relative suffering from Alzheimer's dementia.

Statistical processing of hypotheses was performed using the following statistical methods:

1. interval estimate of proportion

2. Kendall's rank correlation coefficient

3. median

4. descriptive statistics

\section{Analysis and interpretation of results of research}

Table 1 Burden on the carer in terms for mobility

\begin{tabular}{|l|l|c|c|c|c|}
\hline \multicolumn{2}{|c|}{} & \multicolumn{3}{|c|}{ Burden for movement } & \multirow{2}{*}{ Total } \\
\cline { 3 - 6 } \multicolumn{2}{|c|}{} & $\begin{array}{c}\text { Partial } \\
\text { help }\end{array}$ & $\begin{array}{c}\text { Significant } \\
\text { help }\end{array}$ & $\begin{array}{c}\text { Total } \\
\text { dependence }\end{array}$ & \\
\hline Stage of & mild & 10 & 1 & 0 & 11 \\
\cline { 2 - 6 } $\begin{array}{l}\text { Alzheimer's } \\
\text { disease in the patient }\end{array}$ & moderate & 16 & 1 & 1 & 18 \\
\cline { 2 - 6 } & severe & 8 & 8 & 10 & 26 \\
\hline Total & 34 & 10 & 11 & 55 \\
\hline
\end{tabular}


A statistically significant correlation has been found between the stage of the disease and the burden from mobility $(\mathrm{p}<005)$. Kendall's coefficient in this case is $t=052$, which is a strong correlation. Out of 26 carers of patients in a severe stage of the disease, 10 (38 5\%) answered that the patient was completely dependent on their care and therefore they are fully burdened. For patients in an early stage, only $1(91 \%)$ of the carers answered that they were significantly burdened regarding the mobility of the patient.

Table 2 Burden on the carer in terms of care for pressure sores

\begin{tabular}{|l|l|c|c|c|c|}
\hline \multicolumn{2}{|c|}{} & \multicolumn{2}{|c|}{ Burden of care for pressure sores } & \multirow{2}{*}{ Total } \\
\cline { 3 - 6 } \multicolumn{2}{|c|}{} & None & Small & Estensive & \\
\hline \multirow{2}{*}{$\begin{array}{l}\text { Stage of } \\
\text { Alzheimer's } \\
\text { disease in the patient }\end{array}$} & mild & 10 & 1 & 0 & 11 \\
\cline { 2 - 6 } & moderate & 16 & 2 & 0 & 18 \\
\cline { 2 - 6 } & severe & 18 & 6 & 2 & 26 \\
\hline \multicolumn{1}{l|l}{ Total } & 44 & 9 & 2 & 55 \\
\hline
\end{tabular}

Under this item, only 11 carers said their sick relatives had pressure sores. 9 were caring for small pressure sores and 2 carers were caring for extensive pressure sores. $80 \%$ of the respondents did not indicate one of the options, which suggests that 44 patients do not experience pressure sores. Because of the low number of responses, no further analysis was possible.

Table 3 Burden on the carer in terms of cooperating with the patient

\begin{tabular}{|l|l|c|c|c|}
\hline \multicolumn{2}{|c|}{} & \multicolumn{2}{c|}{\begin{tabular}{c} 
Burden from cooperation with the patient \\
\cline { 3 - 5 }
\end{tabular}} & Total \\
\hline \multirow{2}{*}{$\begin{array}{l}\text { Stage of } \\
\text { Alzheimer's } \\
\text { disease in the patient }\end{array}$} & mild & 10 & 1 & 11 \\
\cline { 2 - 5 } & moderate & 17 & 1 & 18 \\
\cline { 2 - 5 } & severe & 9 & 17 & 26 \\
\hline \multicolumn{1}{l|l}{ Total } & & 19 & 55 \\
\hline
\end{tabular}

Statistically significant correlation was found between the stage of the disease and the burden related to cooperation with the patient $(\mathrm{p}<005)$. The Kendall coefficient in this case is $t=0538$, which is a strong correlation. Of the 26 carers who were looking after a patient with severe Alzheimer's, $17(654 \%)$ said that the patient was very difficult to cooperate with. On the other hand, only $1(91 \%)$ of the mild stage patients said co-operation with the patient was very difficult. 36 respondents who were caring for a sick relative in the mild, moderate and severe stages of the illness reported difficulties with co-operation sometimes.

Table 4 Burden on the carer related to faecal incontinence

\begin{tabular}{|c|c|c|c|c|}
\hline & \multicolumn{2}{|c|}{ Burden from faecal incontinence } & \multirow[t]{2}{*}{ Total } \\
\hline & & Sometimes occasionally & Allways & \\
\hline \multirow{3}{*}{$\begin{array}{l}\text { Stage of } \\
\text { Alzheimer's } \\
\text { disease in the patient }\end{array}$} & mild & 10 & 1 & 11 \\
\hline & moderate & 18 & 0 & 18 \\
\hline & severe & 14 & 12 & 26 \\
\hline \multicolumn{2}{|l|}{ Total } & & 13 & 55 \\
\hline
\end{tabular}


A statistically significant correlation was found between the stage of the disease and the burden from faecal incontinence $(\mathrm{p}<005)$. The Kendall coefficient in this case is $t=0422$, which is medium correlation. Of the 26 carers who were caring for a patient with a severe condition, 12 (46 2\%) responded that the patient is always dependent on their care, and therefore they are fully burdened. In patients with a mild condition, only $1(91 \%)$ of the caregivers said they were fully burdened with regard to faecal incontinence.

\section{DISCUSSION}

Overall, the hypothesis has been confirmed. Statistically, we have shown that the relationship between the carer's burden and the stage of the disease in the patient is not the result of random chance. Carers are burdened with the care of a patient with Alzheimer's disease, but the degree of burden depends on the stage of the disease. At the mild stage, the carer's burden is only light, but during the severe stage a high level of care is required for various activities - personal hygiene, mobility, use of the toilet, or patient co-operation. The dependence between the carer's burden and the stage of the disease in the patient was found in the sample group. The statistically significant correlation was due to the dependence between the stage of the disease and the caretaker's burden in all the activities covered by item no. 7 the Svanborg test. There is a strong correlation between the stage of the illness and the burden on the family member arising from the activities of mobility, personal hygiene, eating, use of the toilet, and cooperation with the patient, from which we can conclude that carers are the most burdened in these areas of care for Alzheimer's patients. There was a medium level of correlation between the stage of the disease stage and the burden on carer in terms of urinary and faecal incontinence. The authors of foreign studies report that until the 1980s little attention was paid to families caring for incurably sick members of their families. A significant breakthrough occurred at the end of the $20^{\text {th }}$ century, when gerontologists began to study the burden on families. Klimova 2011defines the burden on the carer as a multidimensional process which is projected into physical, psychological, social and financial dimensions. Caring at home for a patient with a chronic illness is, in most cases means a loss of ability to adapt quickly to an altered situation, the loss active influence on a changed environment, and responding appropriately. In clinical practice it is therefore necessary to pay attention not only to the recipients of care but also to the givers of care. Serfelova Hladekova 2010 in their research focused on the assessment of the burden on the carer in caring for a chronically ill family member in the domestic environment in terms of age, sex, length of care and shared family membership of the carer and the chronically ill patient. Respondents aged 61 to 75 were more affected by the burden. These differences between the younger and older carers may be related to the more frequent occurrence of somatic diseases in older carers and also to the assumption of a greater physical burden on carers of these age groups. Significant differences were also confirmed in terms of the length of care provided. Higher rates of stress were reported by respondents who had provided care for more than 3 years. Meyers et al 2001 pp 7381 states that increasing length of care increases the incidence of psychological problems such as emotional distress, stress, nervousness, fear, depression. Several studies also point to the impact of the length of care on family, financial and social relationships Stoltz 2004 Elmstahl 2006. The most frequent changes include loss of employment, lack of family support, changes in the allocation of tasks among individual family members. Significant differences were also confirmed depending on the carer's family membership with the patient. Higher levels of burden were felt by life partners. Several authors Toth 2005 Hogstel 2006 Ferkova Ilievova 2013 describe the relationship with the relative as one of the determinants influencing the emotional burden on carers. Bragdon and Gamon 2009 p 101 report that the progressive illness of a life partner and subsequent care in the home environment provokes frustration in the carers, it can limit their lifestyle and prospects, it can disturb family relationships because they may feel they have inadequate support from other family members, or if they are unable to provide adequate care for their relative. Tabakova and Vaclavikova (2008) in their work point out that the burden on the carer correlates with self-sufficiency. 


\section{CONCLUSION}

Alzheimer's dementia is a disease that touches only not one person, but the whole family looking after the elderly person. The pillar of care for an Alzheimer's patient is the actual behaviour and approach of the carer. People looking after the victim have to face difficulties, which they manage to a greater or lesser extent, from encountering the diagnosis, through appropriate treatment, to caring for the sick. It is therefore very important that carers have a lot of information and knowledge about the comprehensive care of patients with Alzheimer's disease to help them improve their lives in the home environment.

\section{References:}

1. BRAGDON A D GAMOND (2009) Don't Let the Brain get Old $2^{\text {nd }}$ edition Prague Portal 112 pages ISBN 97880736750042.

2. BRODAL P (2008) Central Nervous System. Structure and Function $1^{\text {st }}$ Slovak edition Martin Osveta 2008517 pages ISBN 97880 80632564.

3. FERKOVA E, ILIEVOVA L (2013) The Known Unknown of Alzheimer's In Nurse ISSN 12100404 vol XXIII issue 4 pp 5658.

4. HOLMEROVA I et al (2004) Non Pharmacological Approaches to Patients Affected by Dementia and Support for Caring Families. In Neurology for Practice vol issue 1 pp 2022.

5. KLIMOVA E (2011) Neurophysiology for Physiotherapists $1^{\text {st }}$ edition Presov M Vaska 108 pages ISBN 9788071658320.

6. KLIMOVA E, MAGUROVA D (2013) Theory and Practice in Caring for an Alzheimer's Patient Presov Grafotlac 235 pages ISBN 978805550936.
7. MEYERS J M et al (2001) The Relationships between Family Primary Caregiver Characteristic and Satisfaction with Hospice Care Quality of Life and Burden Oncology Nursing Forum 2001 vol 2 no 1 pp 7382.

8. RACZ O et al (2006) Basics of Pathological Physiology Kosice Aprilla 243 pages ISBN $809694777 \mathrm{X}$.

9. SERFELOVA R, HLADEKOVA B (2010) Burden on the Carer in the Process of Care for the Chronically Ill In Nursing and Midwifery 20103 vol 1 pp 8992.

10. SHEARDOVA K (2011) Current Possibilities for Dementia Therapy, the Importance of Non-Pharmacological Intervention. In Psychiatry for Practice vol XII issue $3 \mathrm{pp}$ 124126.

11. TABAKOVA M, VACLAVIKOVA P (2008) Burden on the Carer in the Home Environment. In Profession online ISSN 18034330 vol I issue 1 pp 3239.

12. TOKOVSKA M (2013) Cognitive Training in Facilities for Seniors In Nurse and Doctor in Practice vol XII issue 1 pp 3839 ISSN 13359444.

13. TOSNEROVA T (2001) Feelings and Requirements of Carers for Older Family Members. A Guide for Healthcare Workers and Professional Carers. Prague: Clinic for Disorders of Memory 68 pages ISBN 80238 80012.

14. VARSIK P et al (1999) Neurology II Pathogenesis and the Clinic for Nervous Diseases Bratislava Lufema 619 pages ISBN 80 96799169. 